\title{
Sexual Aspects in Paraplegic Patients
}

\author{
N. Francois ${ }^{1}$, M.D. and M. Maury ${ }^{2}$, M.D. \\ ${ }^{1}$ Medical Director, Rehabilitation Centre, Avon and Varennes-farcy, France. \\ Former Assistant, Spinal Cord Injured Unit, Fontainebleau, France. ${ }^{2}$ Former \\ Medical Director, Spinal Cord Injured Unit, Fontainebleau, France
}

\section{Introduction}

The neurophysiology and its physiopathology concerning sexual activity in spinal man or woman, has been the subject of numerous investigations and publications amongst which are those of Bors (1965), Jouannet et al. (1981), and of Donovan (1985). Within the limits of this presentation of such an important subject, one can only give a partial overview. We will envisage successively the lifetime experience of sexual impairments and their aspects in man and woman.

\section{Lifetime experience}

It is important to recall that the sexual act is only part of the vast problem of sexuality. For the paraplegic man and woman, common factors do exist: the influence of age, education, premorbid personality, celibacy or family situation to the time of onset. Eventually relationship difficulties that occur in a wheelchair assume either one's virility or femininity; postural problems depending, amongst others, on the level of the lesion, spasticity and possible deformities. In all cases, the approach of these problems and their counselling should be undertaken in specialised centres, they must be prudent and adapted to each individual situation: whether a congenital or an acquired lesion, complete or incomplete, and the delay since the onset of paraplegia. One must not underestimate the risks of failure linked with the lack of sensation, reflex status and the importance for the search of all kind of compensations: affective, sensory, postural, etc.

\section{The paraplegic man}

\section{Erection}

The occurence of erection can be spontaneous in the majority of paraplegics, but of variable quality. Objective factors, such as its duration, intensity, opportunity and even sometimes the declenching mode does not allow us to 
know with certainty the quality of the sexual act. One can, at least, schematically distinguish between reflexogenic erection, the most frequent, and psychogenic erection, simple intumescence of the penis. One could add the total absence of erections in those with complete lesions of the cauda equina and/or the conus medullaris.

In incomplete lesions, all degrees can be encountered from nearly normal behaviour to that found in those with complete lesions. The main problem, in patients with high lesions, is that of autonomous dysreflexia where it is preferable not to take the risk of triggering the erection or only when the stimulus can be immediately interrupted. The nociceptive effect of the stimulation can provoke an intolerance, even a penile retraction.

\section{How can one improve an erection?}

(a) Masturbation can be helped by a lubricant. Erections can be improved or prolonged by an elastic band carefully placed at the root of the penis.

(b) Vibratory stimulation, in a second stage, is sometimes used immediately as a starter and has allowed us to improve the situation in $30 \%$ of our patients (Francois et al., 1983).

(c) The intra-rectal electrical stimulation procedure is less often used and its results are inconsistent. This technique is not suitable for sexual intercourse (Francois et al., 1983).

(d) Chemical drugs are mostly used by local injections: Phenoxybenzamine (Brindley, 1986), Papaverine, Phentolamine, Timoxamine (Wyndaele et al., 1986). Their secondary side effects must be fully appreciated (priapism, hypotension, vesicosphincteric disturbances, etc.).

Amongst the different models of penile implants proposed, either rigid or semi-rigid, their use and efficiency have been published in the literature. We have no experience of their use, but from the publications we have read, and the results we have seen, we are led to believe that their indications must be rare and prudent, and the benefits, as yet, are not reliably achieved.

\section{Ejaculation}

(a) Ejaculation in the spinal paralysed man is rarely obtained spontaneously; in less than 10 per cent as reported by all authors. When masturbation alone is not sufficient, the first attempt can be by vibratory stimulation, but the condition is that the reflex arc exists, and that the technique used is appropriate. It can be applied by the patient himself (Francois et al., 1983).

(b) In case of failure, in complete sensory upper motor neurone lesions, intra rectal electrical stimulation can be attempted (Francois et al., 1983; Brindley, 1986). Our experimental study on a monkey did show its local innocuity. The technique is delicate and the results are inconsistent but, perhaps, the advantage is that it is the only technique acting by direct stimulation on the sympathetic pathways.

(c) Among the drugs used as stimulants, the use of intrathecal prostigmine has been abandoned. It has been responsible for a few pregnancies (Guttmann $\&$ Walsh, 1971), but also for a certain number of deaths from severe autonomic dysreflexias. Physostigmine (Eserine) by subcutaneous injections is 
not always very well tolerated; Chapelle, promoter of this method which has been used for several years, has recently reported 27 pregnancies for 80 paraplegics (Chapelle, 1987). We tend more and more to use a combination of vibrator application or electroejaculation, with a drug: Desipramine or Maprotiline (Brindley, 1986); Midodrine (Leriche, 1986), or Eserine (Chapelle, 1987).

\section{Procreation}

The sperm in paraplegics is altered compared with the sperm in fertile and unfertile men (Jouannet et al., 1981). The volume, percentage of spermatozoa, whether motile or morphologically normal, are very diminished, but per contra their concentration is very little altered. The technique used seems to influence the volume and this appears to be after electrostimulation, the number of spermatozoa is greater with vibrator application than from masturbation. The secretion of different glandular compartments (fructose secreted by the seminal vesicules, citrate by the prostate, carnitine capted by the epididymis can be missing in the same man). The low motility percentage is the dominant characteristic and also the principle handicap to achieve fertility, as well as sperm bank preservation. In spite of numerous factors, it is possible to be relatively optimistic. We have reported on the result of 43 pregnancies in 112 paraplegics having had at least one ejaculation (Francois et al., 1983). In fact, if one takes into account all the factors which come into play, as well as the gynaecological status of the woman and the couple's perseverence, this result corresponds to $38 \%$ of pregnancies by those really wanting a child. One can note that of 32 artificial inseminations, 22 have been performed by the couples themselves.

New techniques have been recently reported with success, such as implanted hypogastric plexus stimulators and semen capsules (Brindley, 1986).

\section{The paraplegic woman}

Regarding paraplegic women, our experience is more limited. Therefore, we will refer to the work of Rouffet (Jouannet et al., 1981): even in the period of post-traumatic amenorrhoea, which lasts from 3 to 9 months, the couple must know that pregnancy is still possible.

Anticonceptional precautions are therefore indicated. The lack of sensation in the genital area, urinary incontinence (the patient must be advised to empty her bladder before any intercourse), spasticity and in particular those of the adductor muscles, can hinder the sexual act. It is exceptional that the spasticity of the levator ani muscles, which can close the vagina, hinders intromission. Mycobacteriosis is frequent and even more invading as pruritis is absent.

\section{Pregnancy and Delivery}

The paraplegic woman has no neurological reason for being sterile. During pregnancy, certain factors must be taken into consideration. Firstly the sensory impairment, those with lesions below T10 do not feel the contractions of the 
uterus nor the movements of the child. Secondly, below T12, these movements are normally perceived; between $\mathrm{T} 10$ and $\mathrm{T} 12$, these are felt inconsistently. One must also avoid urinary infections and know that pregnancy is always the source of an increase of urinary incontinence. One must avoid the use of an indwelling catheter, which leads to long-term infections and complications (premature birth, foetal hypotrophy).

During delivery, loss of sensation means that no contractions are perceived in patients with lesions which are complete above T11. This leads certain clinicians to hospitalise patients after the 34th week. Generally, at the start of labour, contractions are perceived. At the time of delivery, the main risk in those with lesions above T6 is that of an aggravation of autonomous hyperreflexia, occuring either during the contractions or during the expulsive phase. To prevent this, so as to avoid a caesarean section, it is easier to give an epi- or peridural anaesthetic which also has the advantage of reducing the spasticity of the lower limbs.

\section{Conclusion}

It is only in the past 15 years that doctors really started to study the sexual problems in paraplegia in their whole context. We cannot overemphasise the importance and delicacy of the psychological approach of this problem and the importance of the multidisciplinary teamwork involving the paraplegist, the gynaecologist, the urologist and, especially, the sterility specialist. The myth of the impotency of paraplegic man has disappeared. Everything now shows that the percentage of fertility will increase as the initial complications lessen, and also as different techniques to obtain ejaculation are codified. One would hope that the experimental model represented by the paraplegic will incite us to further research on the role of the nervous system in the control of the genital and reproductive functions in man.

\section{References}

Bors E 1965 Sexual function in patients with spinal cord injury. In: HarRIS P (ed), Spinal Injuries. Morrison and Gibb Ltd, London, pp. 70-79

BRINDLEY GS 1986 Sexual and reproductive problems of paraplegic men. In: ClaRKE JR (ed) Oxford Reviews and Reproductive Biology. 8:214-222

Chapelle PA 1987 A propos de 27 grossesses obtenues grâce à l'Eserine chez les couples dont l'homme est paraplégique. Annales de Réadaptation and de Médicine Physique. In press.

Donovan WH 1985 Sexuality and sexual function. In: BEDBRooK G. M (ed), Lifetime Care of the Paraplegic Patient. Churchill Livingstone, New York, pp. 149-161.

FRANCOIS N, JouANNET P, MAURY M 1983 La fonction génito-sexuelle des paraplégiques. fournal Urologie Néphrologie 89:159-166

Guttmann L, WaLSh JJ 1971 Prostigmine assessment test of fertility in spinal man. Paraplegia $1: 39-50$

Jouannet P, Chapelle PA, Francois N, et al. 1981 La fonction génito-sexuelle. In: Maury M (ed), La Paraplégie chez l'Adulte et chez l'Enfant. Flammarion, Paris, pp. 404-420

Jouannet P, Francois N, MaUry M 1983 Evaluation de la fertilité des hommes paraplégiques. Fournal Urologie E Néphrologie 89:169-171

LERICHE A 1986 Personal communication.

WyNDAELE JJ, De MEYER JM, DE Sy WA, et al. 1986 Intracavernous injection of vasoactive drugs, an alternative for treating impotence in spinal cord injury patients. Paraplegia 24:271275 